\title{
A Case of Ectopic Pregnancy-An Unusual Diagnostic Challenge and Lesson Learnt
}

\author{
Awatuf Elshirif, Seema Sadiq \\ King's College Hospital NHS Foundation Trust, Princess Royal University Hospital, London, UK \\ Email: awatuf.elshirif@nhs.net
}

Received 27 January 2015; accepted 27 March 2015; published 30 March 2015

Copyright (C) 2015 by authors and Scientific Research Publishing Inc.

This work is licensed under the Creative Commons Attribution International License (CC BY). http://creativecommons.org/licenses/by/4.0/

c) (7) Open Access

\begin{abstract}
Ectopic pregnancy has been increasing in frequency over the past 2 decades. The sudden rupture of ectopic pregnancy can lead to haemorrhagic shock and death if not diagnosed and treated in a timely fashion. The first step in the diagnosis of ectopic pregnancy is demonstration of pregnancy by means of a rapidly performed and sensitive qualitative urine test for the beta-subunit of human chorionic gonadotropin (beta-hCG). This case report demonstrates the importance of further consideration of the diagnosis of ectopic pregnancy in the setting of an unusual presentation like per rectal bleed and amenorrhea for three years in the presence of Mirena.
\end{abstract}

\section{Keywords}

Ectopic, Pregnancy, Test, Mirena

\section{Introduction}

The incidence of ectopic pregnancy has increased and the proportion of maternal deaths attributable to ectopic pregnancy increased from 6\% - 10\% during the same period. Ectopic pregnancy should be suspected in every woman of reproductive age who presents with unexplained abdominal pain, a pregnancy test should be first line of investigation with serum beta HCG, irrespective of amenorrhea and vaginal bleeding. A delay or error in the diagnosis of ectopic pregnancy leads to increased risk of mortality and morbidity. A pregnancy test with a transvaginal scan and $\beta$-HCG would improve the likelihood of an early and accurate diagnosis, thus facilitating prompt treatment.

\section{Case Report}

A 38-year-old woman P2+0 presented to Emergency department, with a 2-week history of on-going worsening lower abdominal pain, radiating to her back not responding to simple analgesia with a 2-day history of rectal 
bleeding and pain on defecation. She had no significant past medical or surgical or gynaecological history. She had a Mirena IUS in situ for 3 years for contraception. Her last menstrual period was prior to Mirena insertion. She admitted under surgeons followed by gynaecological review. Her abdomen was tender on palpation. Vaginal examination revealed Perineal scarring, distorted fourchette, with brown vaginal discharge. She was tender in both adnexae with some cervical excitation. Patient was haemodynamically stable. Hb 10.2 g/dL. CRP was mildly raised other investigations were normal. Differential diagnosis of Ano-rectal fistula, diverticulitis and PID was made.

On day one, surgeons examined her under anaesthesia (EUA) which revealed Perineal distortion was secondary to scarring. There was no evidence of ano-vaginal fistula. Sigmoidoscopy performed which was normal.

Second day of admission, a transvaginal scan showed bulky uterus, thickened, irregular endometrium. Mirena was incorrectly placed. Separate to the right ovary a well-defined homogeneous mass contains a gestation sac of 8 weeks.

Urgent Laparoscopy revealed Haemoperitoneum of $2 \mathrm{~L}$. A ruptured $3 \mathrm{~cm}$ right tubal pregnancy was actively bleeding (Figure 1 \& Figure 2). Right salpingectomy performed and 4 units blood transfused.

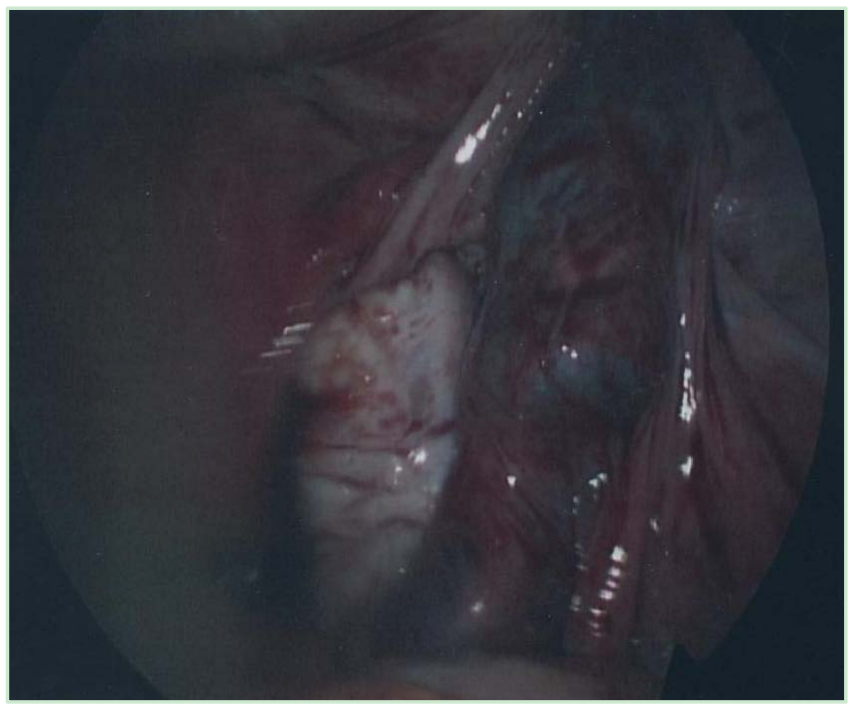

Figure 1. Right ectopic pregnancy.

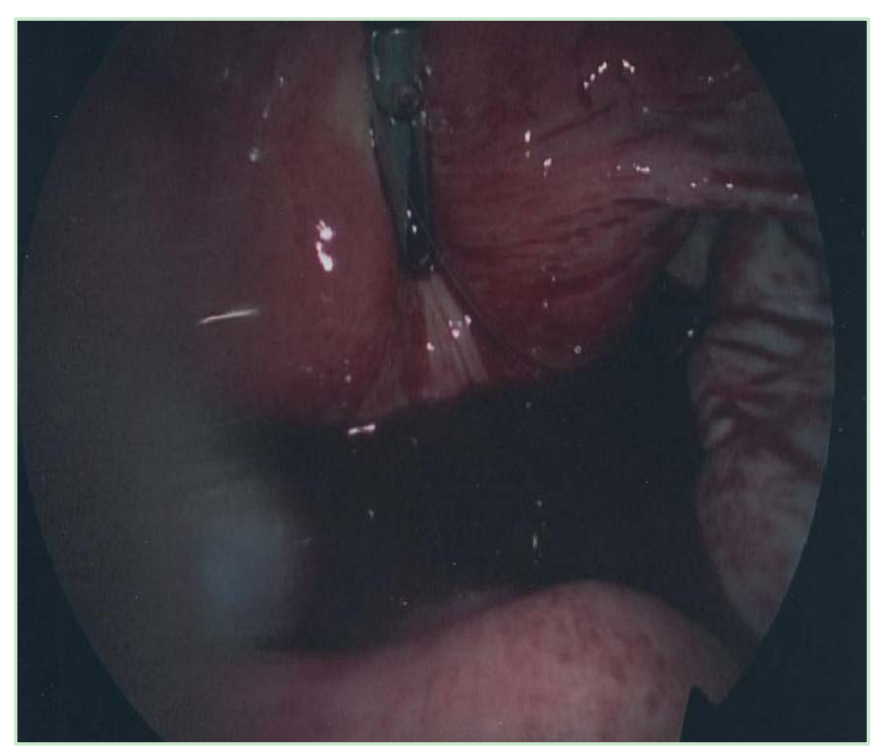

Figure 2. Haemoperitoneum. 
Patient made an excellent recovery and discharged home on day 4. A pregnancy test was not performed at any stage.

\section{Discussion}

Ectopic pregnancy cases are relatively uncommon. Although it comprises only $2 \%$ of all pregnancies [1], the incidence has been on the rise [1] [2]. It is associated with high mortality if diagnosis and management is delayed. Early intervention carries significantly better prognosis [3]. Even surgery can be avoided if management starts before tubal rupture and cardiovascular compromise [4]. Hence, it cannot be over emphasized that early diagnosis is of paramount importance. As illustrated in this case, diagnosis can be easily missed in the absence of classical symptoms of ectopic pregnancy compounded by incomplete patient assessment. The presentations of ectopic pregnancy vary from subtle abdominal pain to profound cardiovascular compromise. Approximately $43 \%$ $55 \%$ of ectopic pregnancies do not present with the classical triad of lower abdominal pain,

Period of amenorrhea and vaginal bleeding [2] [5] [6]. Early symptoms such as abdominal pain although the commonest, is not specific to ectopic pregnancy [7]. About $9 \%-30 \%$ of women may not have abdominal pain at presentation [1] [8]. Differential diagnoses for abdominal pain in a young lady includes appendicitis, miscarriages, pelvic inflammatory disease and ovarian torsion [5]. Absence of a period of amenorrhoea in ectopic pregnancy is rather common and occurs in about $25 \%$ of cases [3] [9]. A detailed menstrual history is important and any sudden change of menstrual pattern should alert the physician to think of the possibility of tubal ectopic pregnancy even in the absence of a clear period of amenorrhoea in women in the reproductive age group [10].

This was a challenging case as the presentation was not the typical sequence of events. Absence of typical symptoms tends to mislead physicians from the possibility of an ectopic pregnancy. Hence, a high index of suspicion for this condition is emphasized. It also highlights the fact that the first episode of abnormal vaginal bleeding in a sexually active woman may be a clue to the underlying diagnosis of ectopic pregnancy and should not be dismissed as dysfunctional uterine bleeding.

\section{Conclusion}

An unusual presentation of abdominal pain and per rectum bleeding resulted in a late diagnosis of ectopic pregnancy. The lesson learnt from this case is despite contraception with abdominal pain and any presentation; a pregnancy test must always be performed in all childbearing age women.

\section{References}

[1] Murray, H., Baakdah, H., Bardell, T. and Tulandi, T. (2005) Diagnosis and Treatment of Ectopic Pregnancy. CMAJ, 173, 905-912. http://dx.doi.org/10.1503/cmaj.050222

[2] Tay, J.I., Moore, J. and Walker, J.J. (2000) Ectopic Pregnancy. BMJ, 320, 916-919. http://dx.doi.org/10.1136/bmj.320.7239.916

[3] Dialani, V. and Levine, D. (2004) Ectopic Pregnancy: A Review. Ultrasound Quarterly, 20, 105-117. http://dx.doi.org/10.1097/00013644-200409000-00005

[4] Murray, H., Baakdah, H., Bardell, T. and Tulandi, T. (2005) Diagnosis and Treatment of Ectopic Pregnancy. CMAJ, 173, 905-912. http://dx.doi.org/10.1503/cmaj.050222

[5] Cunningham, F.G., MacDonald, P.C., Gant, N.F., Gilstrap, L.C. and Leveno, K., Eds. (1993) Williams Obstetrics: Ectopic Pregnancy. 19th Edition, Appleton \& Lange, East Norwalk (CN), 691-720.

[6] Aboud, E. and Chaliha, C. (1998) Nine Year Survey of 138 Ectopic Pregnancies. Archives of Gynecology and Obstetrics, 261, 83-87. http://dx.doi.org/10.1007/s004040050204

[7] Wong, E. and Suat, S.O. (2000) Ectopic Pregnancy: A Diagnostic Challenge in the Emergency Department. European Journal of Emergency Medicine, 7, 189-194. http://dx.doi.org/10.1097/00063110-200009000-00005

[8] Lozeau, A.M. and Potter, B. (2005) Diagnosis and Management of Ectopic Pregnancy. American Family Physician, 72 , 1707-1714.

[9] Aboud, E. (1997) A 5-Year Review of Ectopic Pregnancy. Clinical \& Experimental Obstetrics \& Gynecology, 24, $127-$ 129.

[10] Thomas, L.S. (2002) Ectopic Pregnancy. Top Emerg Med., 24, 12-20. 